\title{
Prototype sphere-on-sphere silica particles for the separation of large biomolecules
}

Authors: Szabolcs Fekete ${ }^{a *}$, Marta Rodriguez-Aller ${ }^{a}$, Alessandra Cusumano ${ }^{b}$, Richard Hayes $^{c}$, Haifei Zhang ${ }^{c}$, Tony Edge ${ }^{d}$, Jean-Luc Veuthey ${ }^{a}$, Davy Guillarme ${ }^{a}$

aSchool of Pharmaceutical Sciences, University of Geneva, University of Lausanne, Bd d'Yvoy 20, 1211 Geneva 4, Switzerland

${ }^{b}$ Department of Pharmacy, University of Bologna, Bologna, Via S. Donato 15, 40127, Italy 'Department of Chemistry, University of Liverpool, Crown Street, Liverpool L69 7ZD, United Kingdom

${ }^{\mathrm{d}}$ Thermo Fisher Scientific, Runcorn, UK

\section{Authors:}

Szabolcs Fekete (corresponding author)

School of Pharmaceutical Sciences, University of Geneva, University of Lausanne, Bd d'Yvoy 20, 1211 Geneva 4, Switzerland

E-mail: szabolcs.fekete@unige.ch

Tel. : +412237963 34

Fax: +412237968 08

Marta Rodriguez-Aller

School of Pharmaceutical Sciences, University of Geneva, University of Lausanne, Bd d'Yvoy 20, 1211 Geneva 4, Switzerland

E-mail: marta.rodriguezaller@unige.ch

Tel. : +41223793302

Fax: +41223796808

Alessandra Cusumano

Department of Pharmacy, University of Bologna, Bologna, Via S. Donato 15, 40127, Italy E-mail: alessandra.cusumano@studio.unibo.it

Tel. : +39 3480433111

Richard Hayes

Department of Chemistry, University of Liverpool, Crown Street, Liverpool L69 7ZD, United Kingdom

E-mail: Richard.Hayes@liverpool.ac.uk 
Tel. : +44517952376

Haifei Zhang

Department of Chemistry, University of Liverpool, Crown Street, Liverpool L69 7ZD, United Kingdom

E-mail: zhanghf@liverpool.ac.uk

Tel. : +44517943545

Tony Edge

Thermo Fisher Scientific, Runcorn, UK

E-mail: tony.edge@thermofisher.com

Tel. : +44 192853448

Fax: +44 1928588106

Jean-Luc Veuthey

School of Pharmaceutical Sciences, University of Geneva, University of Lausanne, Bd d'Yvoy 20, 1211 Geneva 4, Switzerland

E-mail: jean-luc.veuthey@unige.ch

Tel. : +41223796347

Fax: +41223796808

Davy Guillarme

School of Pharmaceutical Sciences, University of Geneva, University of Lausanne, Bd d'Yvoy 20, 1211 Geneva 4, Switzerland

E-mail: davy.guillarme@unige.ch

Tel. : + 41223793463

Fax: +41223796808 


\section{Prototype sphere-on-sphere silica particles for the separation of large biomolecules}

Szabolcs Fekete ${ }^{a \star}$, Marta Rodriguez-Aller ${ }^{a}$, Alessandra Cusumano ${ }^{b}$, Richard Hayes ${ }^{c}$, Haifei Zhang $^{\mathrm{c}}$, Tony Edge ${ }^{\mathrm{d}}$, Jean-Luc Veuthey ${ }^{\mathrm{a}}$, Davy Guillarme ${ }^{\mathrm{a}}$

${ }^{a}$ School of Pharmaceutical Sciences, University of Geneva, University of Lausanne, Bd d'Yvoy 20, 1211 Geneva 4, Switzerland

${ }^{b}$ Department of Pharmacy, University of Bologna, Bologna, Via S. Donato 15, 40127, Italy

'Department of Chemistry, University of Liverpool, Crown Street, Liverpool L69 7ZD, United Kingdom

${ }^{\mathrm{d}}$ Thermo Fisher Scientific, Runcorn, UK

\section{Abstract}

The goal of this study was to evaluate the possibilities offered by a prototype HPLC column packed with $\sim 2.5 \mu \mathrm{m}$ narrow size distribution sphere-on-sphere (SOS) silica particles bonded with C4 alkyl chains, for the analytical characterization of large biomolecules. The kinetic performance of this material was evaluated in both isocratic and gradient modes using various model analytes. The data were compared to those obtained on other widepore stateof-the-art fully core-shell and fully porous materials commonly employed to separate proteins moreover to a reference $5 \mu \mathrm{m}$ wide pore material that is still often used in QC labs. In isocratic mode, minimum reduced plate height values of $h_{\min }=2.6,3.3$ and 3.3 were observed on butylparaben, decapeptide and glucagon, respectively. In gradient elution mode, the SOS column performs very high efficiency when working with fast gradients. This prototype column was also comparable (and sometimes superior) to other widepore stationary phases, whatever the gradient time and flow rate, when analyzing the largest model protein, namely BSA. These benefits may be attributed to the SOS particle morphology, minimizing the intraparticle mass transfer resistance.

Finally, the SOS column was also applied for the analytical characterization of commercial monoclonal antibody (mAb) and antibody-drug conjugate (ADC) samples. With these classes of proteins, the performance of SOS column was similar to the best widepore stationary phases available on the market.

\section{Keywords:}

sphere-on-sphere particles; fractal column; column efficiency; monoclonal antibody; rituximab; brentuximab vedotin 


\section{Introduction}

Highly efficient and faster separations have always been of great interest in high performance liquid chromatography (HPLC), and have become increasingly important in recent years, mainly driven by the challenges of analyzing more complex samples like therapeutic peptides and proteins. Thanks to its high resolving power, reversed phase liquid chromatography (RPLC) is an important and promising tool for the separation of biological macromolecules [1-3]. In such complex separations, the high kinetic performance offered by RPLC plays a key role. By using particulate (packed) columns, the efficiency of large molecule separations can mostly be improved by reducing the intra-particle mass transfer resistance. Since large molecules possess slow diffusivity they spend more time in the intraparticle pores, therefore their bands tend to broaden. To decrease this contribution, nonporous materials or partially porous materials can be applied. However, non-porous materials suffer from limited loading capacity and retention, therefore they have not became widespread in routine analytical labs. A better compromise between efficiency and loadability is the so-called core-shell particle technology.

Core-shell particles consist of a non-porous core surrounded by a porous shell presenting an elevated specific surface. This concept has been introduced in 1967 by Horvath et al. who worked on "pellicular particles" [4]. This material has been known over the years as "pellicular particles", "superficially porous particles", "controlled porosity material", "fused-core particles", "core-shell particles" or "shell particles". Kirkland and coworkers investigated the application of such particles to liquid-liquid and liquid-solid separations which was the starting point of two generations of core-shell packed columns with limited commercial success (Zipax, Corasil, Pellicosil or Poroshell) [5]. The real success of the core-shell technology came only in 2006 with the advent of core-shell columns offering remarkable separation performance and moderated backpressure. Indeed, core-shell particles present unique physical, chemical and mechanical characteristics responsible for the improvement of the van Deemter plot through the decrease of $\mathrm{A}, \mathrm{B}$ and $\mathrm{C}$ terms (decreasing dispersion and resistance to mass transfer). In addition, core-shell particles are easily packed into columns, obtaining dense and homogeneous beds performing efficient separations and avoiding the increase of the backpressure and the need of instrumentation withstanding very high pressures.

The commercial success of this technology led to the commercialization of different column dimensions, chemistries and porosities, from numerous providers. The manufacture of coreshell particles is based on the production of non-porous cores which are subsequently enveloped by the porous shell. Special attention has to be paid to particle size and particle size distribution; pore dimension and porosity; as well as shell thickness and surface functionality [6]. 
Unger et al. used for the first time core-shell particles for the successful separation of complex proteins mixtures under gradient elution in 1986 [7]. More than 20 years later, a number of investigations demonstrated that the core-shell technology was particularly well suited for peptides and proteins analyses offering fast separations, excellent resolution and limited backpressure [8]. In this context, pore size was found to play a key role since large pores provided higher resolution [9].

Recently, an interesting alternative to core-shell particles was proposed [10,11]. The so called sphere-on-sphere (SOS) approach provides a simple and fast one-pot synthesis in which the thickness, porosity and chemical substituents of the shell can be controlled by using the appropriate reagents and conditions [12]. A study was carried out to find out how these particles were formed, by imaging the particles during the course of the reaction. Microscopic images suggested that a two stage nucleation process occurred. The first stage, not unlike core-shell synthesis, was the formation of the core microsphere. The second stage was nucleation of nanoparticles on the surface of these microspheres. SOS particles have been shown to be microporous with a pore diameter of less than $2 \mathrm{~nm}$. However, while the surface of the material might not exhibit significant porosity, when packed into a HPLC column, the spaces between surface nanospheres provide superficial macroporosity. It has been proposed that for large molecules, larger pores as well as reduction of the shell thickness can be advantageous, due to the shorter diffusion distance and greater access to the surface area of the material [13,14]. Recently $2.9 \mu \mathrm{m}$ SOS particles were demonstrated to have similar chromatographic performance than commercial core-shell materials $(2.6 \mu \mathrm{m})$ when separating standard peptides and proteins of various sizes (e.g. lysozyme, myoglobin, ovalbumin...), while reducing the operating time and pressure [10].

The aim of this study was to evaluate the possibilities of prototype SOS columns for the separation of biologics. Column performance was studied in both isocratic and gradient elution modes with several model solutes. Our purpose was to compare the achievable peak capacity of the SOS column to other widepore state-of-the-art fully porous and core-shell materials commonly employed for protein separations. Real life samples of native, reduced and digested monoclonal antibodies (mAbs) and antibody-drug conjugates (ADCs) were analyzed using the SOS column, to demonstrate its possibilities. To the best of our knowledge, no data on the applicability of such materials have been reported for mAbs and ADCs.

\section{Experimental}

\subsection{Instrumentation}


Chromatographic experiments were performed on a Waters Acquity I-Class UPLC system (Waters, Milford, MA, USA). The instrument was equipped with a binary solvent manager, autosampler, thermostated column compartment, and UV detector. The autosampler was equipped with a flow through needle injection system. The average extra-column peak variance of our system was found to be around $\sigma_{\mathrm{ec}}{ }^{2} \sim 1-3 \mu \mathrm{L}^{2}$. The UV detector operated with a $500 \mathrm{~nL}$ flow cell, set to $240 \mathrm{~nm}$ (for butylparaben) and $280 \mathrm{~nm}$ (for peptides and proteins) and $40 \mathrm{~Hz}$ sampling rate. Data acquisition, data handling and instrument control were performed by Empower Pro 2 (Waters, Milford, MA, USA) software. Then, data were exported and edited using MS Excel.

\subsection{Chemicals and columns}

Water was obtained from a MilliQ Purification System from Millipore (Bedford, MA, USA). Acetonitrile (gradient grade), trifluoroacetic acid (TFA, puriss p.a.), dithiothreitol (DTT, $\geq 99.0$ $\%$ ), uracil, parabens (methyl-, ethyl-, propyl- and butyl-) and protein standards such as glucagon ( $\mathrm{MW} \sim 3.5 \mathrm{kDa}$ ), insulin (from bovine pancreas, $\mathrm{MW} \sim 5.7 \mathrm{kDa}$ ), myoglobin (from equine skeletal muscle, MW 17.7 kDa) and albumin (BSA from bovine serum, MW $\sim 69.3$ $\mathrm{kDa}$ ), cetyltrimethylammonium bromide ( $\geq 98 \%)$, 3-mercaptopropyl trimethoxysilane (95\%), ammonium hydroxide $(28-30 \%$ ammonia basis, ACS reagent), imidazole ( $\geq 99 \%$, ACS reagent) and trimethylsilylimidazole $(\geq 98 \%)$ were purchased from Sigma-Aldrich (Buchs, Switzerland). Butyl(chloro)dimethyl silane (>97\%) was purchased from Tokyo Chemical Industry. Model peptides, including $\mathrm{CH}-866$ (MW=1311.5 g/mol), $\mathrm{CH}-868$ (MW=1311.5 $\mathrm{g} / \mathrm{mol}), \mathrm{CH}-869$ (MW=1277.5 $\mathrm{g} / \mathrm{mol})$ and $\mathrm{CH}-870$ (1295.5 $\mathrm{g} / \mathrm{mol})$ decapeptides were purchased from ChinaPeptides Co., Ltd (Shanghai, China). These model peptides are analogues of the commercial therapeutic peptide, triptorelin in which only one amino acid was altered. Food and Drug Administration (FDA) and European Medicines Agency (EMA) approved therapeutic IgG1 monoclonal antibody (rituximab, mabthera), and antibody drug conjugate $(A D C)$ brentuximab-vedotin were kindly provided by Alain Beck from the Center of Immunology Pierre Fabre (Saint-Julien en Genevois, France).

Prototype SOS (sphere-on-sphere) C4 (100 mm x $2.1 \mathrm{~mm}, \sim 2.5 \mu \mathrm{m})$ columns were kindly provided by the University of Liverpool and Thermo Fisher Scientific, Runcorn, UK. Aeris Widepore C18 (100 mm x $2.1 \mathrm{~mm}, 3.6 \mu \mathrm{m})$ column were purchased from Phenomenex Inc (Torrance, CA, USA). Halo Protein C4 $(150 \times 2.1 \mathrm{~mm}, 3.4 \mu \mathrm{m})$ column was a generous gift from Stephanie Schuster, Advanced Materials Technology (Wilmington, DE, USA). Agilent Zorbax 300SB-C18 $5 \mu \mathrm{m}(150 \times 2.1 \mathrm{~mm})$ column was obtained from Agilent Technologies (Santa Clara, CA, USA). Acquity BEH-300 C18 column with a particle size of $1.7 \mu \mathrm{m}(150 \times$ $2.1 \mathrm{~mm}, 300 \AA$ ) was purchased from Waters (Milford, MA, USA). 


\subsubsection{Synthesis of SOS particles}

Polyvinylpyrrolidone (PVP, 10k MW, $2.5 \mathrm{~g}$ ) and cetyltrimethylammonium bromide (CTAB, $0.125 \mathrm{~g}$ ) were dissolved in distilled water $(50 \mathrm{~mL})$. Methanol $(80 \mathrm{~mL})$ was added with stirring, followed by ammonium hydroxide $(1.4 \%, 20 \mathrm{~mL})$. Solution stirred for 15 minutes before addition of 3-mercaptopropyl trimethoxysilane (MPTMS, $4 \mathrm{~mL}$ ) in $0.5 \mathrm{~mL}$ portions 1 minute apart. Reaction was stirred overnight.

Narrow size distribution SOS particles were collected by centrifugation and washed with distilled water $(3 \times 50 \mathrm{~mL})$, then methanol $(3 \times 50 \mathrm{~mL})$ before drying under vacuum at $60{ }^{\circ} \mathrm{C}$. Particles were calcined at $550{ }^{\circ} \mathrm{C}$ and at $1000{ }^{\circ} \mathrm{C}$. Calcination at $550{ }^{\circ} \mathrm{C}$ resulted in a microporous material with large surface area while calcination at $1000{ }^{\circ} \mathrm{C}$ resulted in nonporous material with low surface area. The average particle size was measured as 2.83 and $2.13 \mu \mathrm{m}$ with a particle size distribution of $d_{90 / 10}=1.31$ and 1.44 respectively.

Since better results were observed with the microporous material (higher peak capacity for proteins) therefore data obtained only with this material (calcined at $550{ }^{\circ} \mathrm{C}$ ) are discussed later. For clarity, a nominal particle size of $\sim 2.5 \mu \mathrm{m}$ is indicated fro the SOS material.

\subsubsection{Bonding}

Functionalisation: SOS particles $(1 \mathrm{~g})$ were dispersed in toluene $(7.5 \mathrm{~mL})$ by sonication. Imidazole $(0.1 \mathrm{~g})$ and butyl(chloro)dimethyl silane (C4, $0.2 \mathrm{~g})$ were added and vessel sealed. The mixture was heated at $120^{\circ} \mathrm{C}$ for 20 minutes using a microwave reactor. Resultant SOSC4 particles were washed on sintered glass filter with toluene $(20 \mathrm{~mL})$, methanol $(20 \mathrm{~mL})$, $50 \%$ aqueous methanol $(20 \mathrm{~mL})$ and methanol $(20 \mathrm{~mL})$. Particles were dried under vacuum at $80^{\circ} \mathrm{C}$.

Endcapping: SOS-C4 particles (1 g) were dispersed in toluene $(7.5 \mathrm{~mL})$ by sonication. Trimethylsilylimidazole $(0.2 \mathrm{~g})$ was added and the vessel sealed. The mixture was heated at $120^{\circ} \mathrm{C}$ for 20 minutes using a microwave reactor. Resultant SOS-C4 particles were washed on sintered glass filter with toluene $(20 \mathrm{~mL})$, methanol $(20 \mathrm{~mL})$, methanol/water $(1: 1,20 \mathrm{~mL})$ and methanol $(20 \mathrm{~mL})$. Particles were dried under vacuum at $80^{\circ} \mathrm{C}$.

\subsubsection{Column packing}

SOS-C4 particles were packed into $100 \times 2.1 \mathrm{~mm}$ stainless steel columns using a Knauer $\mathrm{K} 1900$ packing pump at 650 bar. The silica suspension was prepared by dispersing $0.5 \mathrm{~g}$ of the functionalised particles in a $30 \mathrm{~mL}$ solution of $72: 8: 20(\mathrm{~V} / \mathrm{V} / \mathrm{V})$ chloroform : methanol : isopropanol.

\subsection{Methodology}




\subsubsection{Measuring permeability, porosity and column efficiency}

The column permeability was determined with the following equation:

$$
K_{V}=\frac{u_{0} \cdot \eta \cdot L}{\Delta P}
$$

where $K_{V}$ is the column permeability, $u_{0}$ is the mobile phase linear velocity, $\eta$ is the mobile phase viscosity, $L$ is the column length and $\Delta P$ is the column pressure drop. Permeability data were obtained after correction for the system pressure drop.

The linear velocity and the total column porosity $\left(\varepsilon_{T}\right)$ were determined using the following equation:

$u_{0}=\frac{L}{t_{0}}=\frac{4 F}{\varepsilon_{T} d_{c}^{2} \pi}$

where $t_{0}$ is the column dead time, $F$ the mobile-phase flow-rate and $d_{c}$ the column diameter.

Column efficiency in isocratic elution mode was investigated by constructing plate height plots with different test solutes (butylparaben, decapeptide and glucagon). The following equations were used for the calculations:

$h=A v^{1 / 3}+\frac{B}{v}+C v$

$h=\frac{H}{d_{p}}$

where $H$ is the theoretical plate height, $d_{p}$ the particle size of the column packing material, $A-$ $C$ are constants accounting for band broadening and $h$ is the reduced plate height. For the calculations the average measured particle size was considered that was slightly different from the nominal $2.5 \mu \mathrm{m}$. Reduced linear velocity $(v)$ was determined according to the next formula:

$v=\frac{u_{0} d_{p}}{D_{m}}$

where $D_{m}$ is the solute molecular diffusion coefficient and was determined by using the Wilke-Chang equation [15].

Separation impedance $(E)$ allows comparison of total column performance and considers not only the achieved plate count (or plate heights), but also the analysis time $\left(t_{0}\right)$ and column permeability. This dimensionless parameter is an absolute measure of column performance. Separation impedance was determined by using the next formula [16]:

$$
E=\frac{t_{0}}{N^{2}} \frac{\Delta P}{\eta}=\frac{H^{2}}{K_{V}}
$$

where $N$ is the observed plate number. Viscosity was calculated by using the equations derived from Chen and Horvath [17] and was assumed to be independent of the pressure. 
In gradient elution mode, peak capacities were experimentally determined from the gradient time $\left(t_{g}\right)$ and the average measured peak width at $50 \%$ height $\left(W_{50 \%}\right)$. The following equation was used to estimate the peak capacity based on peak width at $4 \sigma$, corresponding to a resolution of $R_{S}=1$ between consecutive peaks:

$$
P=1+\frac{t_{g}}{1.7 \cdot w_{50 \%}}
$$

To avoid the imprecision associated with the measurement of peak widths at baseline for proteins often containing closely related variants (i.e. for a heterogeneous sample), the peak width at half height was preferred in this study. This way, the impurities present in the sample, and partially resolved from the main component, did not confuse the measurement.

\subsubsection{Sample preparation, mobile phase composition}

The isocratic mobile phase consisted of $83 / 17(\mathrm{v} / \mathrm{v} \%)$ water/acetonitrile for the mixture of uracil and parabens. For measuring the isocratic column efficiency of large analytes (decapeptides and glucagon), mixtures of water (0.1\%TFA)/acetonitrile ( $0.1 \%$ TFA) 83/17 $(\mathrm{v} / \mathrm{v} \%)$ and $75 / 25(\mathrm{v} / \mathrm{v} \%)$ were used as mobile phases (at $30 \stackrel{\circ}{\circ})$. For the gradient separation of test proteins (insulin, myoglobin and BSA), IgG1 and ADC samples, the mobile phase "A" was $0.1 \%$ TFA in water, while the mobile phase "B" was $0.1 \%$ TFA in acetonitrile.

The stock solutions of uracil and parabens were prepared in water/acetonitrile 80/20 (v/v\%) $(1000 \mu \mathrm{g} / \mathrm{ml})$. The solutions for the chromatographic runs were diluted from the stock solutions with the mobile phase. The final concentration of the test solutions was $10 \mu \mathrm{g} / \mathrm{ml}$. The stock solutions of decapeptides and glucagon were made in $0.1 \%$ TFA in water (1000 $\mu \mathrm{g} / \mathrm{ml})$. The injected solutions were diluted with water $(100 \mu \mathrm{g} / \mathrm{ml})$.

The stock solutions of model proteins were prepared in water $(1000 \mu \mathrm{g} / \mathrm{ml})$ except insulin which was dissolved in 80/20 (v/v\%) water/acetonitrile $(0.1 \%$ TFA) solvent. The stock solutions were sonicated for $0.5 \mathrm{~min}$ in ultrasonic bath then homogenized (for $5 \mathrm{sec}$ with vortex mixer). After that, aliquots of stock solutions of each solute were transferred into low volume insert of sample vial and diluted to $100 \mu \mathrm{g} / \mathrm{ml}$ with water.

The IgG1 monoclonal antibody (mAbThera) was diluted from the commercial solution to 2 $\mathrm{mg} / \mathrm{mL}$ in water. The intramolecular disulphide bonds were reduced with DTT. $0.05 \mathrm{mg}$ of DDT was added to $100 \mu \mathrm{L} \operatorname{lgG} 1$ solution $(2 \mathrm{mg} / \mathrm{ml})$, then it was incubated at $30 \stackrel{\circ}{ } \mathrm{C}$ for $60 \mathrm{~min}$. The protein was completely converted to the light chain (Lc) and heavy chain (Hc) components of the antibody. Hydrophobic interaction chromatography (HIC) is the reference technique for measuring drug to antibody ratio (DAR), but RPLC can also be used to understand the positional isomer distribution of ADC. The positional isomers are often separated and assessed from the RPLC analysis of reduced ADC. Brentuximab-vedotin was 
diluted to $2 \mathrm{mg} / \mathrm{mL}$ in water and then reduced by adding $0.05 \mathrm{mg}$ DDT to $100 \mu \mathrm{L}$ ADC solution and incubated at $30^{\circ} \mathrm{C}$ for $60 \mathrm{~min}$.

\subsubsection{Chromatographic conditions}

At first, the efficiency of prototype SOS columns were investigated by constructing their $h-u_{0}$ plots and estimating their minimum reduced plate height values $\left(h_{\min }\right)$.

A small volume $(1 \mu \mathrm{L})$ of different molecular weight compounds such as parabens, decapeptides and glucagon was injected during the flow study. The flow rate was varied from 0.025 to $0.8 \mathrm{~mL} / \mathrm{min}$. The column temperature was set to $30 \stackrel{\circ}{\mathrm{C}}$ for all analytes. Detection was carried out at $240 \mathrm{~nm}$ for parabens and at $280 \mathrm{~nm}$ for decapeptides and glucagon.

Peak capacities were measured with model proteins (i.e. insulin, myoglobin and BSA) applying gradient elution of 20 to $60 \% \mathrm{~B}$ at a flow rate of 0.25 and $0.40 \mathrm{~mL} / \mathrm{min}$ and a column temperature of $50^{\circ} \mathrm{C}$. Gradient times were varied between 6 and $75 \mathrm{~min}$, followed by $1.5 \mathrm{~min}$ equilibration. $1 \mu \mathrm{L}$ of sample was injected and detection was carried out at $280 \mathrm{~nm}$.

Method was developed for intact and reduced IgG1. The chromatographic conditions were optimized by a systematic variation of the gradient span and steepness, column temperature and flow-rate. It was found that on the $100 \mathrm{~mm}$ long SOS C4 column, a $5 \mathrm{~min}$ long gradient from 24 to $37 \% \mathrm{~B}$ while on the $150 \mathrm{~mm}$ long Aeris C18, BEH300 C18 and Halo Protein C4 a $7.5 \mathrm{~min}$ long gradient from 27 to $40 \% \mathrm{~B}$, at a flow-rate of $0.4 \mathrm{~mL} / \mathrm{min}$ and $80{ }^{\circ} \mathrm{C}$ were appropriate to separate the related Lc and Hc fragments. $1 \mu \mathrm{L}$ of sample was injected and detection was carried out at $280 \mathrm{~nm}$.

Systematic method development was also performed for the reduced ADC (brentuximabvedotin) sample. It was found that a $12 \mathrm{~min}$ long gradient provided reasonable separation of the peaks on the $100 \mathrm{~mm}$ long SOS C4 column while on the $150 \mathrm{~mm}$ long columns a $18 \mathrm{~min}$ long gradient was applied. ADC sample was analyzed at $80{ }^{\circ} \mathrm{C}$ with $27-42 \% \mathrm{~B}$ gradient on the SOS 4 and with $30-45 \% \mathrm{~B}$ gradient on the Aeris C18. BEH $300 \mathrm{C} 18$ and Halo Protein C4 columns at flow-rate of $0.4 \mathrm{~mL} / \mathrm{min}$. $0.5 \mu \mathrm{L}$ of sample was injected and detection was carried out at $280 \mathrm{~nm}$.

\section{Results and discussion}

\subsection{Efficiency in isocratic elution mode, porosity, permeability and impedance}

Figure 1 shows the obtained $h-v$ plots for butylparaben, decapeptide and glucagon observed on the SOS column. Minimum reduced plate height values of $h_{\min }=2.6,3.3$ and 3.3 were observed on the three model compounds, respectively. These values are somewhat higher that can be obtained with state-of-the-art core-shell materials [18-21]. With those materials, generally $h_{\min }$ values around $1.2-1.8$ are expected, depending on the particle structure, 
solute and experimental conditions. A column packed perfectly with non-porous particles should provide $h_{\min } \sim 1$. In our case we were clearly far from this value, suggesting that packing quality was not perfect. Indeed, column packing procedure has not yet been optimized with this propotype material, a generic method was follwed and probably this is the reason of observing higher reduced plate height minimum value than expected. Certainly the packing can be improved by further optimization.

The morphology of the SOS particles is shown in figure 2. It can be seen that there is a central solid core, with spheres attached to the central core, and in some circumstances even smaller silica spheres attached to the initial layer of smaller solid spheres. Nitrogen absorption experiments demonstrate that the specific surface area is $248 \mathrm{~m}^{2} / \mathrm{g}$. This value perhaps seems to be quite high but please note, that particles were calcined at $550{ }^{\circ} \mathrm{C}$, that results in microporous structure. In previous studies, much lower surface areas were reported for SOS particles but those were calcined at significantly higer temperetare (e.g. $100{ }^{\circ} \mathrm{C}$ ) and possess non-porous structure. The average diameter of the whole particle is around $2.5 \mu \mathrm{m}$. This comprises of solid spheres attached to the central core of approximately $2.0 \mu \mathrm{m}$ in diameter. It can be seen that there are several layers of the solid spheres, and in the example shown in figure 2, there are spheres on spheres, although the overall shape of the particle is still very much spherical in nature. Thus, the surface area is increased when compared to a traditional spherical non-porous material, however, it does not possess the same accessible surface area as seen with the fully porous materials, due to the lack of the pore structure.

Theoretically, with core-shell particles, the intra-particle diffusivity (that corresponds to the $C_{P}$ term in the van Deemter or Knox equations) depends on the ratio of the diameters of the solid core to that of the whole particle $\left(d_{p}\right)$. As this ratio $(\rho)$ increases, the mass transfer kinetics becomes faster across the particles [21]. Figure 3 shows the theoretical reduction in reduced plate heights $(h)$ on a relative scale for the intra-particle mass transfer resistance term $\left(h_{C p}\right)$ as a function of particle structure $(\rho)$. Based on this plot, clearly much lower plate heights can be expected for current wide pore core-shell particles compared to fully porous materials of the same particle diameter. (Please note, that this representation does not say anything about the relative contribution of the dispersive phenomena $\left(h_{C p}\right)$ to the total $h$.) The intra-particle mass transfer resistance is important mostly for large molecules when the diffusion time inside the particles is much longer but it is not so critical for small molecules. This is the reason why we thought that the sphere-on-sphere particle structure is probably beneficial for large proteins. Additionally, the longitudinal diffusion ( $B$ term of the van Deemter or Knox equations) is also advantageous for SOS and core-shell particle structure compared to fully porous particles, but for large molecules the $B$-term contribution to band broadening is not very important (practically negligible for larger than $10 \mathrm{kDa}$ molecules). 
The total porosity of the SOS columns were measured as $\varepsilon_{T}=0.55-0.57$ (based on the elution time of unretained solute: uracil) that is very close to values of current wide pore coreshell materials. The average column permeability of different batches was determined as $K_{v}$ $=1.09^{*} 10^{-10} \mathrm{~cm}^{2}$, that is quite favourable. The lowest separation impedance value was observed with butylparaben as $E_{\min } \sim 4800$. In RPLC, the best state-of-the-art columns perform typically $E_{\min }$ values between 3000-5000.

\subsection{Efficiency in gradient elution mode}

In the following section, a systematic study presents the achievable peak capacity of the prototype SOS (C4) column. Its efficiency was compared to that of columns packed with widepore fully porous particles ( $5 \mu \mathrm{m}, \mathrm{C} 18)$, one column packed with sub-2 $\mu \mathrm{m}$ fully porous particles (300 $\AA, \mathrm{C} 18)$, one column packed with $3.6 \mu \mathrm{m}$ wide-pore core-shell particles (C18) and one column of $400 \AA 3.4 \mu \mathrm{m}$ core-shell C4 particles, for gradient protein separations. This methodical comparison allowed us to study the effect of both pore size and particle structure (fully porous or shell type) on the performance in gradient separation mode. Please note that stationary phases of C18 and C4 were selected since both are often used for RP protein separations. In practice, proteins are separated in gradient elution mode at elevated temperature. Elevated temperature is beneficial because it decreases the secondary interactions between residual silanols and positively charged biomolecules. Moreover, the use of high temperatures strongly enhances analyte diffusion [16,22]. Furthermore, ionpairing reagents such as TFA should be added to the mobile phase to increase the efficiency of protein separation [23-25]. To emulate real-life separations, we applied $50 \stackrel{\circ}{\circ}$ as column temperature, added $0.1 \%$ TFA into the mobile phase and used gradient spans which are fairly common in the current practice. The test solution was a mixture of model proteins (insulin, myoglobin and BSA) having different molecular weights comprised between 5.7 and $66.8 \mathrm{kDa}$.

The influence of the gradient steepness and linear velocity on column performance was investigated under several gradient elution conditions. These experimental variables were directly related to the mobile phase flow-rate and the gradient time duration which are often used to adjust a proper separation in practical work. The former has a direct influence on the peak width, while gradient duration plays an important role on the resolution under gradient conditions, as it affects the retention factor of the solute in the mobile phase composition upon elution.

The peak capacity of $150 \mathrm{~mm}$ long narrow bore Waters BEH300 C18 and Zorbax 300SB C18 columns were obtained in previous studies [18] and the data are used for comparison purposes. 
Peak capacity values for the prototype SOS column were calculated and plotted against the gradient time according to Eq. (7) at two different flow rates ( $F=0.25$ and $0.40 \mathrm{ml} / \mathrm{min}$ ) (Figure 4). These results illustrate how the experimental conditions affect the achievable peak capacity and demonstrate significant differences in column performance for different type of proteins. It should be noted that these conditions are not meant to maximize the peak capacity as sometimes higher peak capacity can be achieved by choosing longer gradient times. Instead, we merely wanted to identify a set of conditions that allows a fair comparison within a practically acceptable time frame, for commonly used narrow bore columns.

Based on figure 4 , the peak capacity varied between $P=160$ and 255 at $0.25 \mathrm{~mL} / \mathrm{min}$, and between $P=140$ and 245 at $0.4 \mathrm{~mL} / \mathrm{min}$ with insulin. With myoglobin, peak capacity of $P=$ $150-240$ and $P=135-235$ were observed at 0.25 and $0.4 \mathrm{~mL} / \mathrm{min}$, respectively. The difference in peak capacity between 0.25 and $0.4 \mathrm{~mL} / \mathrm{min}$ was lower than $10 \%$. This is probably due to the structure of the SOS particle and its reduced intra-particle mass transfer resistance. This feature enables to work at relatively high flow rates - without significant loss in peak capacity - and therefore fast protein separations can be performed. With the largest test protein (BSA), peak capacity between $P=70$ and 80 was achieved and did not change significantly with the gradient time and flow rate. It again suggests the decreased mass transfer resistance and shows that this SOS material becomes particularly relevant for large proteins analysis.

Figure 5 shows comparative chromatograms observed with the SOS C4, Aeris C18, Halo Protein C4 and BEH300 C18 columns when injecting insulin (as model solute). The chromatograms were recorded at $0.4 \mathrm{~mL} / \mathrm{min}$ flow rate and at short gradient time. Please note, that chromatograms are plotted against the apparent retention factor since the columns possess different lengths. The gradient program was scaled for the different column lengths in agreement with geometrical transfer rules. The peak widths are comparable on the different columns, moreover the chromatograms also justify the use of half height peak width (see E.q.7) since related product is eluting in the tail of the main insulin peak and makes the determination of baseline peak width inaccurate. The SOS C4 column provided the lowest retention that is expected despite its relatively high surface area $\left(248 \mathrm{~m}^{2} / \mathrm{g}\right)$ since the micropores are not accessible for the solutes. Moreover, lower retention was observed with small test solutes too (parabens, decapeptides). Otherwise the use of C4 or C18 ligands do not determine alone the retention of proteins. As an example - with agreement with previous results [18] - the retention of proteins on BEH300 C18 is often lower than on other C4 and C18 wide pore phases. Beside the length of the alkyl chain, probably ligand density, carbon load and other features such as the possibility of secondary interactions with residual silanols all impact the retention. 
Figure 6 shows a comparison of peak capacity obtained with myoglobin on five different widepore columns. To have comparable results with these columns of different length (100 and $150 \mathrm{~mm}$ ) and porosity at different flow rates, the rules of linear solvent strength (LSS) theory and geometrical method transfer were applied $[26,27]$. The next formula was used to calculate the gradient steepness $(s)$ for the given conditions:

$$
s=\left(\phi_{e}-\phi_{0}\right) \cdot\left(\frac{L}{t_{g}-t_{0}}\right) \cdot u_{0}=\beta \cdot L \cdot u_{0}
$$

where $\Phi_{0}$ is the initial mobile phase composition and $\Phi_{e}$ is the final mobile phase composition, and $\beta$ is the so-called time steepness of the linear gradient. The applied conditions can be used to directly compare the efficiency of these columns of different length (100 and $150 \mathrm{~mm}$ ) in gradient elution mode. However, the experimentally observed peak capacity values are still not comparable since peak capacity also depends on column length. Therefore, the peak capacities extrapolated to 1 meter column length $\left(P_{M}\right)$ were considered in this comparison. When maintaining the gradient steepness constant, the following formula can be written:

$$
P_{M}=P \cdot \sqrt{\frac{100}{L}}
$$

Where $P_{M}$ is the peak capacity extrapolated to $1 \mathrm{~m}$ length and $L$ is the column length in $\mathrm{cm}$. During the experiments $\Phi_{e^{-}} \Phi_{0}$ was kept constant (40\%) for all columns. When comparing the efficiency of these columns, the peak capacities per meter were plotted against the gradient span (expressed in time/column length dimension such as min/meter). In this case, the gradient span $(S)$ was calculated as:

$$
S=t_{g}\left(\frac{100}{L}\right)
$$

Whatever the gradient span, the Halo Protein, Aeris and BEH 300 columns outperformed the $\sim 2.5 \mu \mathrm{m}$ SOS and $5 \mu \mathrm{m}$ fully porous materials at $0.25 \mathrm{~mL} / \mathrm{min}$ (Figure $6 \mathrm{~A}$ ). Whatever the gradient steepness, the SOS column outperformed the $5 \mu \mathrm{m}$ Zorbax column. With steep gradient $(S<100)$, the SOS column performed similar peak capacity to Aeris and BEH 300 columns. A similar ranking was observed at $0.4 \mathrm{~mL} / \mathrm{min}$ (Figure $6 \mathrm{~B}$ ), but for fast gradients ( $S$ $<200$ ), the SOS column clearly outperformed the Aeris column. The ranking of columns was different when analysing larger proteins. With BSA, at $0.25 \mathrm{~mL} / \mathrm{min}$, the $\mathrm{SOS}$ column provided the highest peak capacity when $S<250$ (Figure $7 \mathrm{~A}$ ). With longer gradients, the SOS column showed very similar efficiency to the Aeris Widepore material. When working at $0.4 \mathrm{~mL} / \mathrm{min}$, the SOS column outperformed all the other columns whatever the gradient span (Figure 7 B) except the $400 \AA$ Halo Protein column. The peak capacity observed with the $\sim 2.5 \mu \mathrm{m}$ SOS material was about twice higher than those obtained with conventional fully 
porous $5 \mu \mathrm{m}$ particles (Zorbax 300). It clearly proves the benefit of sphere-on-sphere particle structure over fully porous particles, particularly for the analytical characterization of large biomolecules. In addition, the peak capacity attained with the SOS column is mostly beneficial when performing fast gradients.

\subsection{Separation of $m A b$ and $A D C$ fragments}

In this section, the possibilities of the prototype sphere-on-sphere material is presented for the analysis of large biomolecules (mAb and ADC).

Characterization of a bio-pharmaceutical product, performed with appropriate analytical techniques, provides useful information on purity and/or protein stability in its formulation. Antibody heterogeneity is related to conformational isoforms. The reduction of the disulfide bonds of IgGs and then the RPLC analysis of the reduced fragments is a commonly used test to determine whether the conformational variants are disulfide-related or not.

Figure 8 shows representative chromatograms of intact and reduced rituximab, obtained under the optimized conditions. As shown, the variability of rituximab is related to the $\mathrm{Hc}$, rather than Lc. The quality of the separation is comparable to what can be obtained on silicabased or hybrid state-of-the-art wide-pore phases. Peak capacities of $P=45$ and 68 were obtained with the $100 \mathrm{~mm}$ long SOS column with a 5 minutes long gradient for the intact and reduced $\mathrm{mAb}$, respectively. We also have to mention that the commercial columns performed somewhat better "fine structure” of closely related species (e.g. better resolved heavy-chain species).

One of the most important quality attributes of an ADC is the average number of drugs that are conjugated because this determines the amount of "payload" that can be delivered to the tumor cell and can directly affect both safety and efficacy [28]. A variety of methods have been used to measure this attribute. Among them, RPLC is an often applied technique, and reduced ADCs are routinely analysed by RPLC. On figure 9, the separation of reduced brentuximab-vedotin is shown. The separationwas performed at $80{ }^{\circ} \mathrm{C}$ (12 and $18 \mathrm{~min}$ gradients on 100 and $150 \mathrm{~mm}$ long columns, respectively) and provided quite good separation. An average peak capacity of $P=117$ was measured for this sample with the 100 $\mathrm{mm}$ long SOS column that is comparable to those obtained with other state-of-the-art wide pore columns. On the chromatogram, the LO, L1, H0, H1, H2 and $\mathrm{H} 3$ fragments were well separated $(\mathrm{L}$ and $\mathrm{H}$ denote $\mathrm{Lc}$ and $\mathrm{Hc}$, and the number denotes the number of drugs attached to each chain). This RPLC chromatographic profile is often observed for IgG1 type ADCs [29]. A few isomers were resolved from the $\mathrm{H} 1, \mathrm{H} 2$ and $\mathrm{H} 3$ peaks. For brentuximab vedotin a similar chromatogram was reported by Le et al., but the separation required 64 min in conventional HPLC conditions [30]. Here, by using recent narrow bore wide pore columns, the analysis time was drastically reduced. 
Due to the lower retention on the SOS column, the mobile phase composition has to be adjusted to have similar retention of those obtained on commercially available core-shell and fully porous materials. In these two applications, the acetonitrile content of the mobile phase was decreased by $3 \%$ in order to perform similar retention to the other columns (see section 2.3.3.).

\section{Conclusion}

In this work, a prototype C4 column packed with $\sim 2.5 \mu \mathrm{m}$ narrow size distribution sphere-onsphere (SOS) silica particles was tested for the analysis of biopharmaceuticals. This SOS column was found to be particularly well suited for the analysis of large biomolecules, since each particle is composed of a relatively large solid inner core surrounded by a significant number of small spheres of silica. Because this phase is composed of microporous material, the intra-particle mass transfer resistance is minimized, leading to excellent kinetic performance (micropores are not accessible for analytes). In addition, thanks to the special particle morphology, the surface area seems to be sufficient to achieve reasonable loading capacity and retention, however mobile phase composition has to be adjusted. Further studies are planned to study the loading capacity of SOS particle structure in details.

This prototype material was successfully applied for the analysis of model proteins and for therapeutic monoclonal antibody (mAb) and antibody-drug conjugate (ADC) samples. The kinetic performance of SOS material was systematically compared to that of other wide pore state-of-the-art fully porous and core-shell materials commonly employed to separate proteins. As illustrated, the performance achieved with the SOS column was comparable and sometimes better than other columns dedicated to proteins analysis and packed with particles ranging between 1.7 and $5 \mu \mathrm{m}$.

\section{Acknowledgement}

The authors acknowledge Dr Alain Beck (Pierre Fabre, Saint-Julien Genevois, France) for providing monoclonal antibody and antibody drug conjugate samples.

Davy Guillarme wishes to thank the Swiss National Science Foundation for support through a fellowship to Szabolcs Fekete (31003A_159494). 


\section{References:}

[1] A. Staub, D. Guillarme, J. Schappler, J.-L. Veuthey, S. Rudaz, Intact protein analysis in the biopharmaceutical field, J. Pharm. Biomed. Anal. 55 (2011) 810-822.

[2] S. Fekete, J.-L. Veuthey, D. Guillarme, New trends in reversed-phase liquid chromatographic separations of therapeutic peptides and proteins: Theory and applications, J. Pharm. Biomed. Anal. 69 (2012) 9-27.

[3] S. Fekete, D. Guillarme, Ultra-high performance liquid chromatography for the characterization of therapeutic proteins, Trends Anal. Chem. 63 (2014) 76-84.

[4] C. Horvath, S.R. Lipsky, Fast Liquid Chromatography: An investigation of operating parameters and the separation of nucleotides on pellicular ion exchangers, Anal. Chem. 39 (1967) 1422-1428.

[5] G. Guiochon, F. Gritti, Shell particles, trials, tribulations and triumphs, J Chromatogr A 1218 (2011) 1915-1938.

[6] R. Hayes, A. Ahmed, T. Edge, H. Zhang, Core-shell particles: Preparation, fundamentals and applications in high performance liquid chromatography, J Chromatogr. A 1357 (2014) 36-52.

[7] K.K. Unger, G. Jilge, J.N. Kinkel, M.T.V. Hearn, Evaluation of advanced silica packings for the separation of biopolymers by high-performance liquid chromatography II. Performance of non-porous monodisperse 1.5- $\mu \mathrm{m}$ Silica beads in the separation of proteins by reversedphase gradient elution high-performance liquid chromatography, J Chromatogr. 359 (1986) 61-72.

[8] A. Staub, D. Zurlino, S. Rudaz, J.-L. Veuthey, D. Guillarme, Analysis of peptides and proteins using sub-2 $\mu \mathrm{m}$ fully porous and sub $3-\mu \mathrm{m}$ shell particles, J Chromatogr. A 1218 (2011) 8903-8914.

[9] B.M. Wagner, S.A. Schuster, B.E. Boyes, J.J. Kirkland, Superficially porous silica particles with wide pores for biomacromolecular separations, J Chrom A 1264 (2012) 22-30.

[10] R. Hayes, P. Myers, T. Edge, H. Zhang, Monodisperse sphere-on-sphere silica particles for fast HPLC separation of peptides and proteins, Analyst 139 (2014) 5674-5677.

[11] A. Ahmed, H. Ritchie, P. Myers, H. Zhang, One-Pot synthesis of spheres-on-sphere silica particles from a single precursor for fast HPLC with low back pressure, Adv. Materials, 24 (2012) 6042-6048.

[12] A. Ahmed, W. Abdelmagid, H. Ritchie, P. Myers, H. Zhankg, Investigation on synthesis of spheres-on-sphere silica particles and their assessment for high performance liquid chromatography applications, J Chromatogr A 1270 (2012) 194-203. 
[13] L. E. Blue and J. W. Jorgenson, $1.1 \mu \mathrm{m}$ superficially porous particles for liquid chromatography. Part I: Synthesis and particle structure characterization, J. Chromatogr. A, 1218 (2011) 7989-7995.

[14] K. K. Unger, R. Skudas and M. M. Schulte, Particle packed columns and monolithic columns in high-performance liquid chromatography-comparison and critical appraisal, J. Chromatogr. A, 1184 (2008) 393-415.

[15] C.R. Wilke, P. Chang, Correlation of diffusion coefficients in dilute solutions, AIChE J. 1 (1955) 264-270.

[16] P.A. Bristow, J.H. Knox, Standardization of test conditions for high performance liquid chromatography columns, Chromatographia 10 (1977) 279-289.

[17] $\mathrm{H}$. Chen, Cs. Horvath, Standardization of test conditions for high performance liquid chromatography columns, J. Chromatogr. A 705 (1995) 3-20.

[18] S. Fekete, R. Berky, J. Fekete, J.L. Veuthey, D. Guillarme, Evaluation of a new wide pore core-shell material (AerisTM WIDEPORE) and comparison with other existing stationary phases for the analysis of intact proteins, J. Chromatogr. A 1236 (2012) 177-188. [19] S. Fekete, D. Guillarme, Kinetic evaluation of new generation of column packed with 1.3 $\mu \mathrm{m}$ core-shell particles, J. Chromatogr. A 1308 (2013) 104- 113.

[20] S.A. Schuster, B.M. Wagner, B.E. Boyes, J.J. Kirkland, Optimized superficially porous particles for protein separations, J. Chromatogr. A 1315 (2013) 118- 126.

[21] F. Gritti, G. Guiochon, The mass transfer kinetics in columns packed with Halo-ES shell particles, J. Chromatogr. A 1218 (2011) 907-921.

[22] S. Heinisch, J.L. Rocca, Sense and nonsense of high-temperature liquid chromatography, J. Chromatogr. A 1216 (2009) 642-658.

[23] R.A. Everley, T.R. Croley, J. Ultra-performance liquid chromatography/mass spectrometry of intact proteins, J. Chromatogr. A 1192 (2008) 239-247.

[24] A. Shibue, C.T. Mant, R.S. Hodges, Effect of anionic ion-pairing reagent concentration (1-60 mM) on reversed-phase liquid chromatography elution behaviour of peptides, J. Chromatogr. A 1080 (2005) 58-67.

[25] A. Shibue, C.T. Mant, R.S. Hodges, Effect of anionic ion-pairing reagent hydrophobicity on selectivity of peptide separations by reversed-phase liquid chromatography, J.

Chromatogr. A 1080 (2005) 68-75.

[26] Snyder LR (1980) Gradient elution in HPLC: Advances and Perspectives, Vol. 1 (C. Horvath, ed.) Academic Press, New York

[27] Snyder LR, Kirkland JJ, Glajch JL (1997) Practical HPLC Method Development, second ed., John Wiley \& Sons Inc., New York

[28] A. Wakankar, Y. Chen, Y. Gokarn, F. S Jacobson, Analytical methods for physicochemical characterization of antibody drug conjugates, MAbs. 3 (2011) 161-172. 
[29] B. Wiggins, L.L. Shin, H. Yamaguchi, G. Ratnaswamy, Characterization of cysteinelinked conjugation profiles of immunoglobulin G1 and immunoglobuline G2 antibody-drug conjugates, J. Pharm. Sci. 104 (2015) 1362-1372.

[30] L.N. Le, J.M.R. Moore, J. Ouyang, X. Chen, M.D.H. Nguyen, W.J. Galush, Profiling antibody drug conjugate positional isomers: a system-of equations approach, Anal. Chem. 84 (2012) 7479-7486. 


\section{Figure captions}

Figure 1. $h$-v plots, observed on sphere-on-sphere column with butylparaben, decapaptide $(\mathrm{CH}-869)$ and glucagon. Mobile phase consisted of 83/17 (v/v\%) water/acetonitrile for butylparaben. Mixtures of water (0.1\%TFA)/acetonitrile (0.1\% TFA) $83 / 17$ (v/v\%) and 75/25 $(\mathrm{v} / \mathrm{v} \%)$ were used as mobile phases for the decapeptide and glucagon, respectively. Temperature was set to $30^{\circ} \mathrm{C}$. Other experimental conditions were described in sections 2.3.2. and 2.3.3.

Figure 2. Scanning electron microscopic image of sphere-on-sphere prototype particles.

Figure 3. The theoretically expected reduction of reduced plate height contributions of the $h_{C p}$ term as a function of particle structure $(\rho)$ for core-shell morphology. The yellow area indicates the $\rho$ range for commercially available standard pore particles while the pink area shows the $\rho$ range for commercially available wide pore materials.

Figure 4. peak capacity plots, observed with sphere-on-sphere column by injecting insulin, myoglobin and BSA at a flow rate of 0.40 and $0.25 \mathrm{~mL} / \mathrm{min}$. Column: Prototype SOS (sphereon-sphere) C4 (100 mm x $2.1 \mathrm{~mm}, \sim 2.5 \mu \mathrm{m})$, mobile phase A: $0.1 \%$ TFA, mobile phase B: $0.1 \%$ TFA in acetonitrile. Gradient program: $20-60 \% \mathrm{~B}$, mobile phase temperature: $50{ }^{\circ} \mathrm{C}$. Gradient times were varied between 6 and 75 min.

Figure 5. Comparative chromatograms observed by injecting insulin as test protein. Columns: Prototype SOS (sphere-on-sphere) C4 (100 mm x $2.1 \mathrm{~mm}, \sim 2.5 \mu \mathrm{m}$ ), Halo Protein C4 $(150 \times 2.1 \mathrm{~mm}, 3.4 \mu \mathrm{m}), \mathrm{BEH} 300 \mathrm{C} 18(150 \times 2.1 \mathrm{~mm}, 1.7 \mu \mathrm{m})$ and Aeris Widepore C18 $(150 \times 2.1 \mathrm{~mm}, 3.6 \mu \mathrm{m})$. Mobile phase A: $0.1 \%$ TFA, mobile phase B: $0.1 \%$ TFA in acetonitrile. Gradient program: $20-60 \% \mathrm{~B}$, mobile phase temperature: $50{ }^{\circ} \mathrm{C}$. Gradient times: 6.7 and $10 \mathrm{~min}$ on 100 and $150 \mathrm{~mm}$ long columns, respectively.

Figure 6. Comparison of peak capacities obtained with myoglobin at a flow rate of 0.25 $\mathrm{mL} / \mathrm{min}(\mathrm{A})$ and $0.40 \mathrm{~mL} / \mathrm{min}(\mathrm{B})$. Columns: Prototype SOS (sphere-on-sphere) C4 (100 mm x $2.1 \mathrm{~mm}, \sim 2.5 \mu \mathrm{m})$, Halo Protein C4 (150 x $2.1 \mathrm{~mm}, 3.4 \mu \mathrm{m})$, BEH300 C18 (150 x $2.1 \mathrm{~mm}$, $1.7 \mu \mathrm{m})$ and Aeris Widepore C18 $(150 \times 2.1 \mathrm{~mm}, 3.6 \mu \mathrm{m})$. Other experimental conditions were described in sections 2.3.2. and 2.3.3. 
Figure 7. Comparison of peak capacities obtained with BSA at a flow rate of $0.25 \mathrm{~mL} / \mathrm{min}(\mathrm{A})$ and $0.40 \mathrm{~mL} / \mathrm{min}(\mathrm{B})$. Columns: similar to Figure 6 . Other experimental conditions were described in sections 2.3.2. and 2.3.3.

Figure 8. Representative chromatograms of MabThera (intact and reduced). Columns: Prototype SOS (sphere-on-sphere) C4 (100 mm x $2.1 \mathrm{~mm}, \sim 2.5 \mu \mathrm{m})$, Halo Protein C4 (150 x $2.1 \mathrm{~mm}, 3.4 \mu \mathrm{m}), \mathrm{BEH} 300 \mathrm{C} 18(150 \times 2.1 \mathrm{~mm}, 1.7 \mu \mathrm{m})$ and Aeris Widepore C18 (150 x 2.1 $\mathrm{mm}, 3.6 \mu \mathrm{m})$. Mobile phase A: $0.1 \%$ TFA, mobile phase B: $0.1 \%$ TFA in acetonitrile. Flowrate of $0.4 \mathrm{~mL} / \mathrm{min}$, gradient: $24-37 \% \mathrm{~B}$ in $5 \mathrm{~min}$ on the SOS column and $27-40 \% \mathrm{~B}$ on the other columns, temperature: $80^{\circ} \mathrm{C}$, UV detection was carried out at $280 \mathrm{~nm}$.

Figure 9. Representative chromatogram of reduced ADC (Brentuximab-Vedotin). Columns: Prototype SOS (sphere-on-sphere) C4 (100 mm x $2.1 \mathrm{~mm}, \sim 2.5 \mu \mathrm{m})$, Halo Protein C4 (150 x $2.1 \mathrm{~mm}, 3.4 \mu \mathrm{m}), \mathrm{BEH} 300 \mathrm{C} 18(150 \times 2.1 \mathrm{~mm}, 1.7 \mu \mathrm{m})$ and Aeris Widepore C18 $(150 \times 2.1$ $\mathrm{mm}, 3.6 \mu \mathrm{m})$. Mobile phase A: $0.1 \%$ TFA, mobile phase B: $0.1 \%$ TFA in acetonitrile. Flowrate of $0.4 \mathrm{~mL} / \mathrm{min}$, gradient: $27-42 \% \mathrm{~B}$ in $12 \mathrm{~min}$ on the SOS column and $30-45 \% \mathrm{~B}$ on the other columns, temperature: $80^{\circ} \mathrm{C}$, UV detection was carried out at $280 \mathrm{~nm}$. 


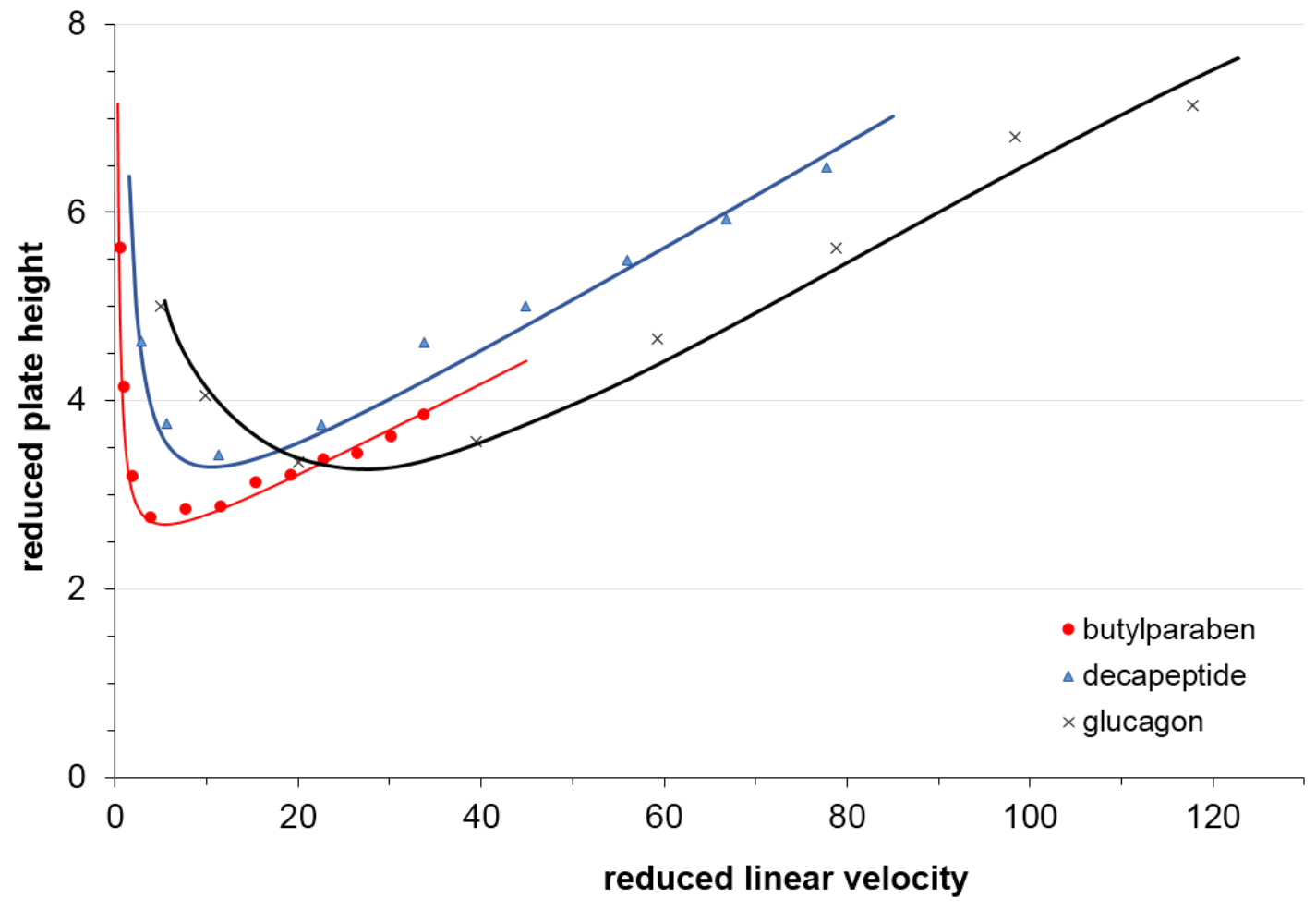

Figure 1. 


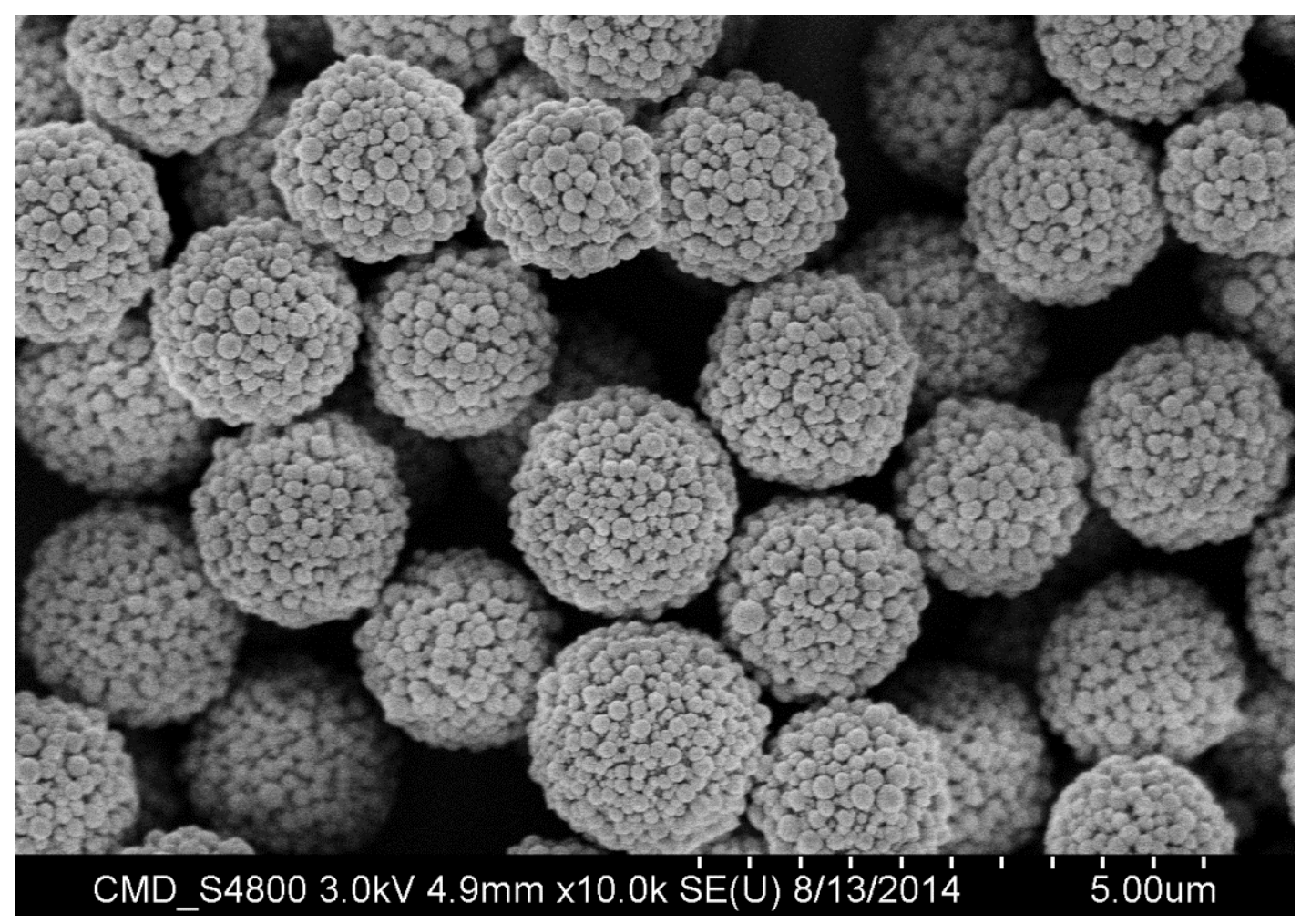

Figure 2. 


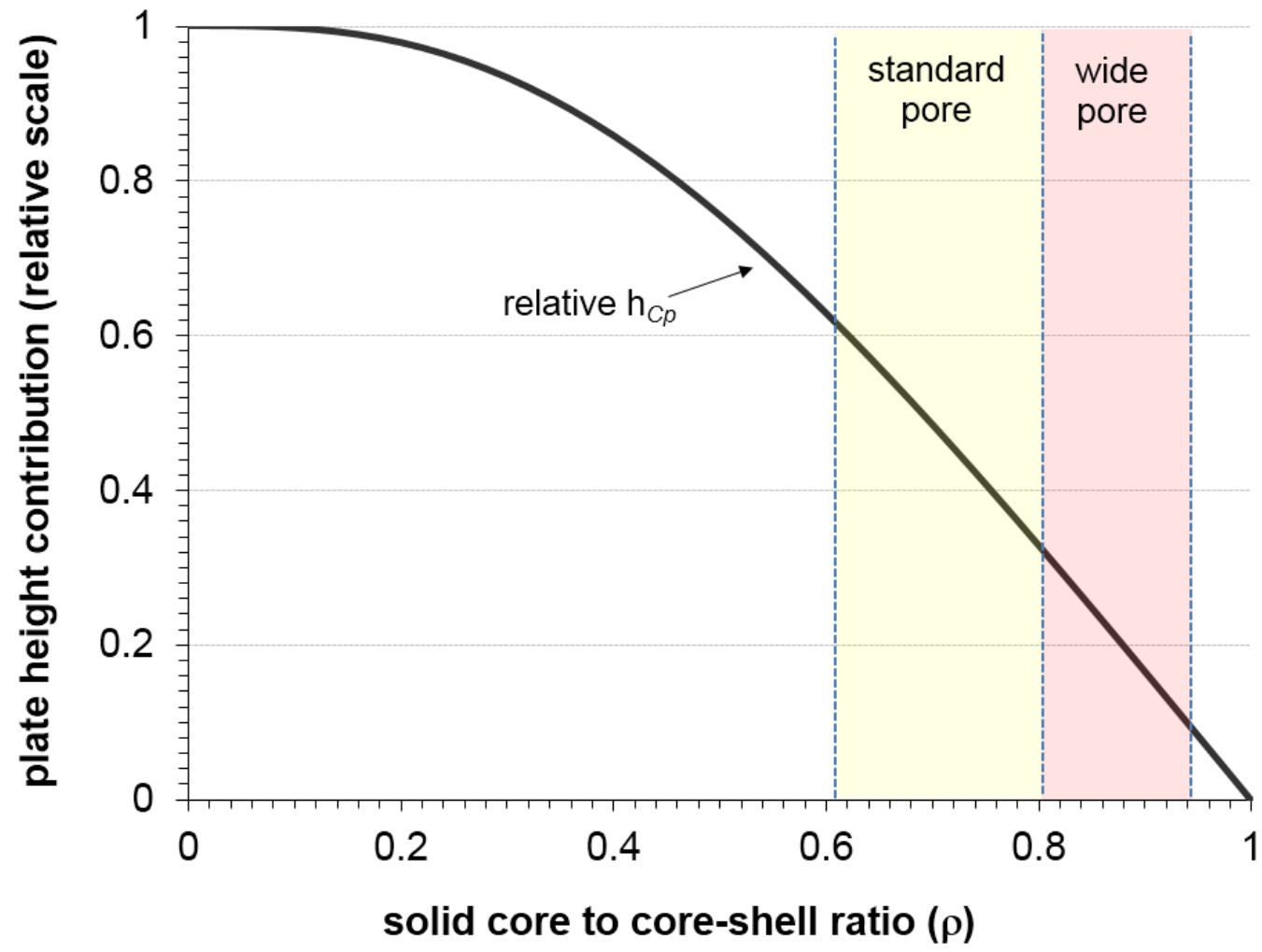

Figure 3. 


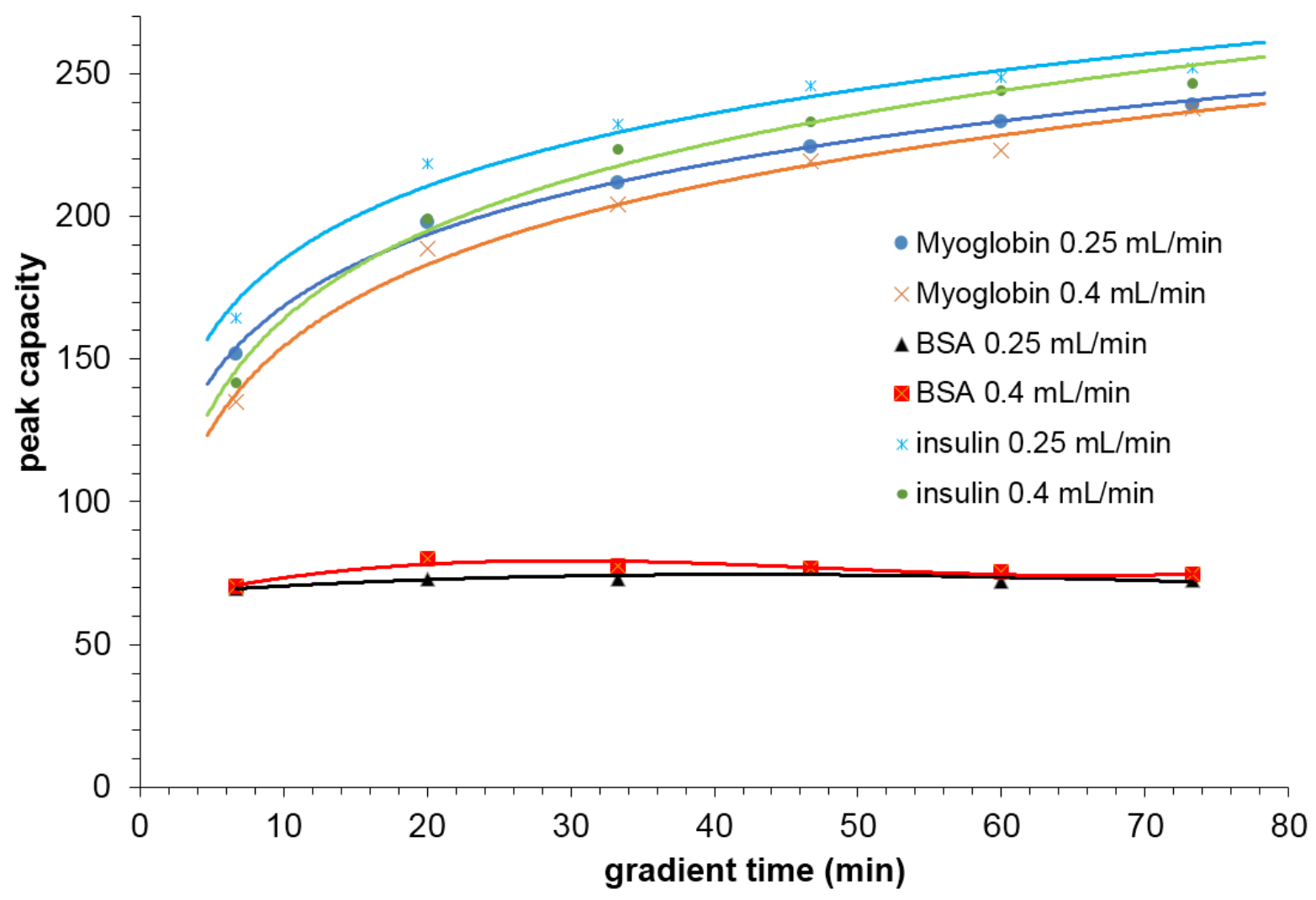

Figure 4. 


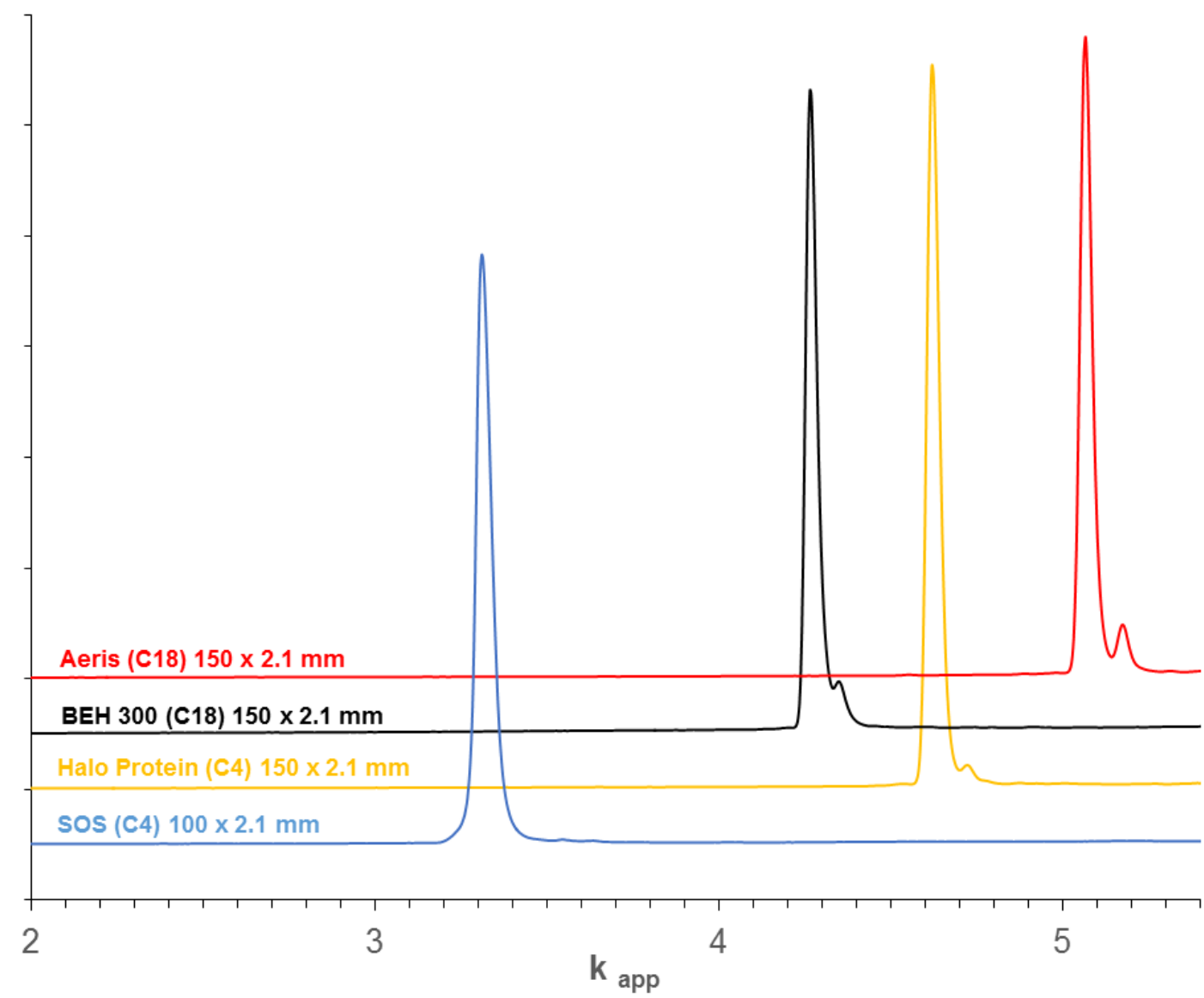

Figure 5. 

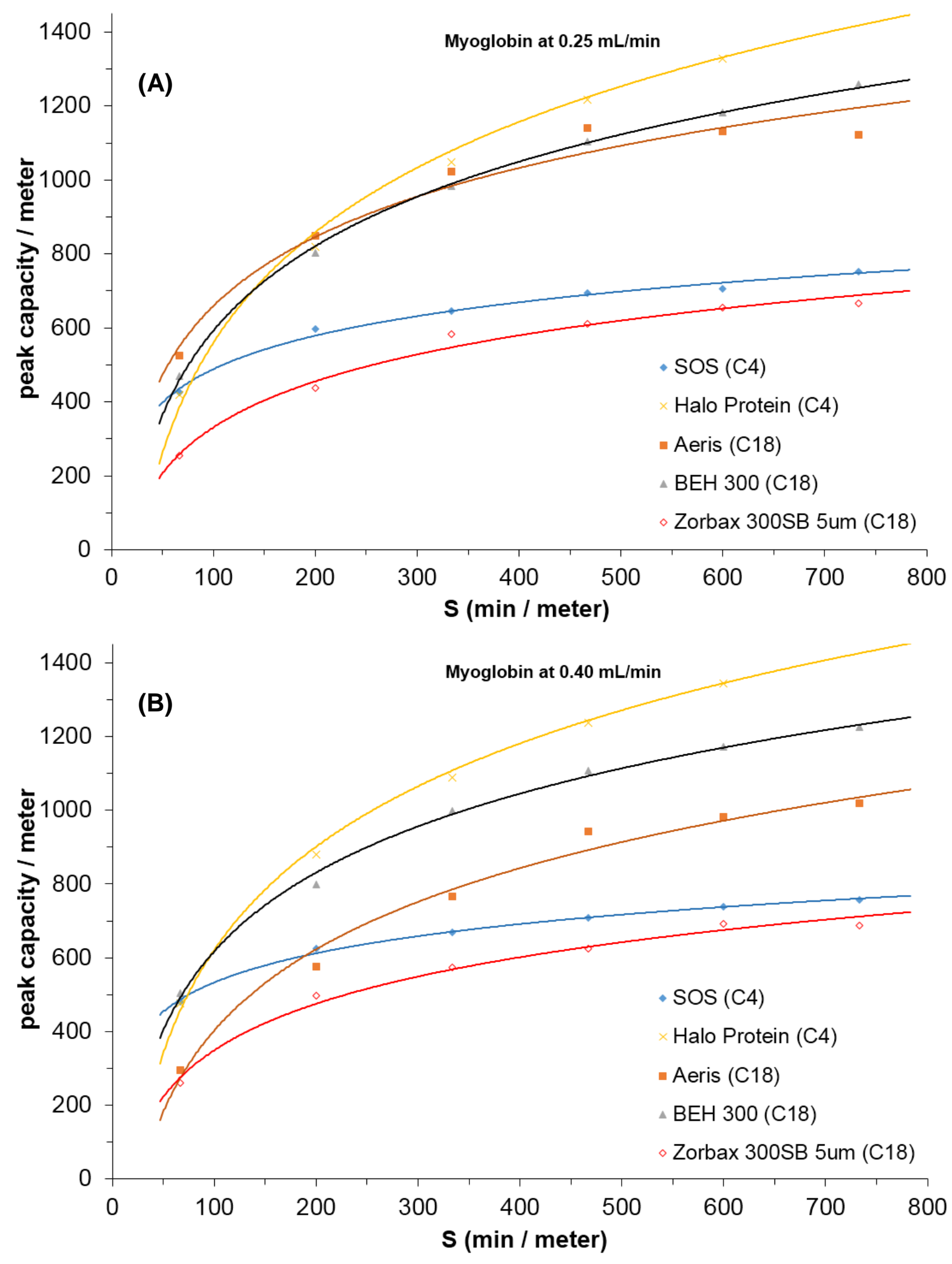

Figure 6. 

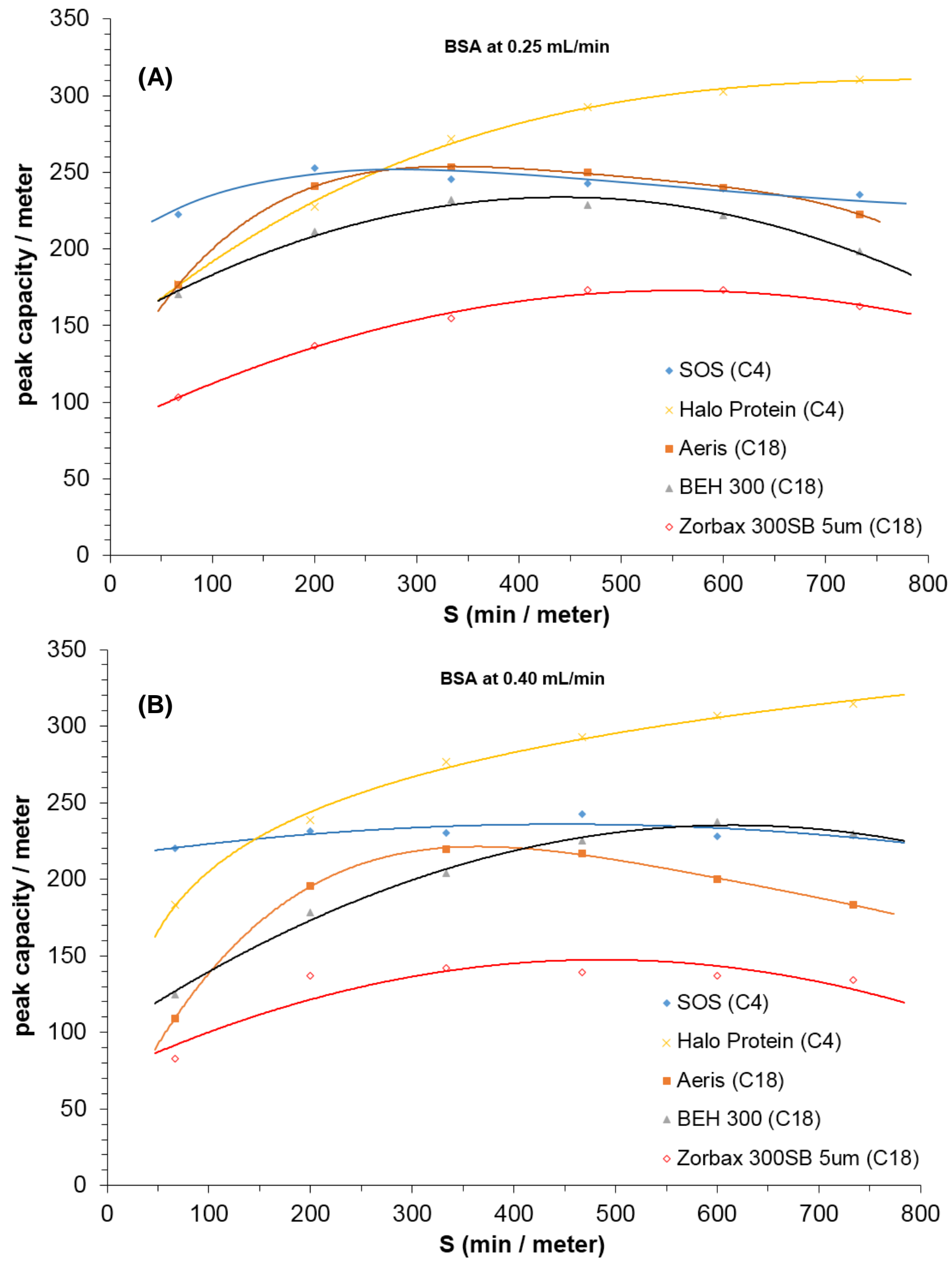

Figure 7. 


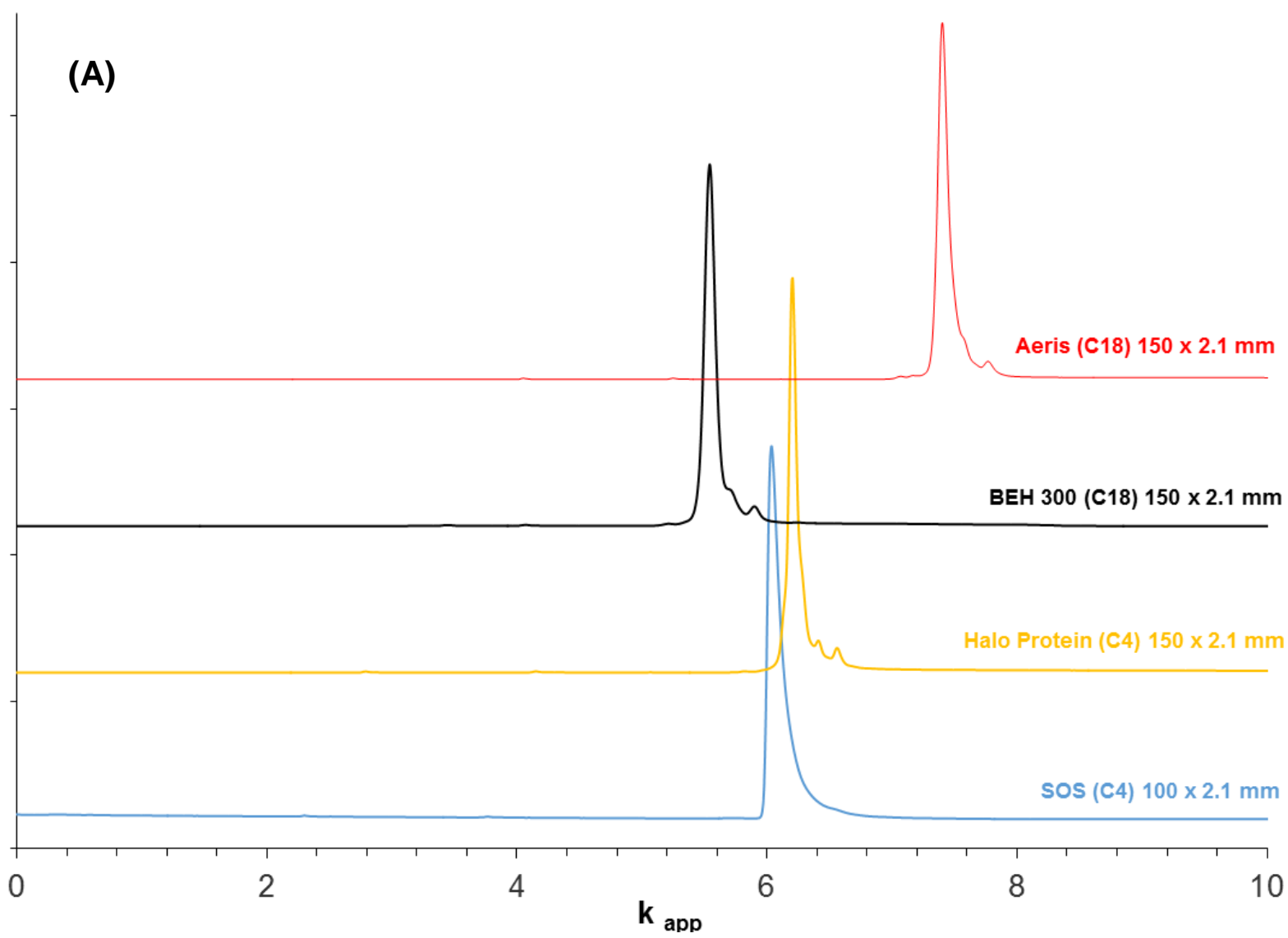

(B)

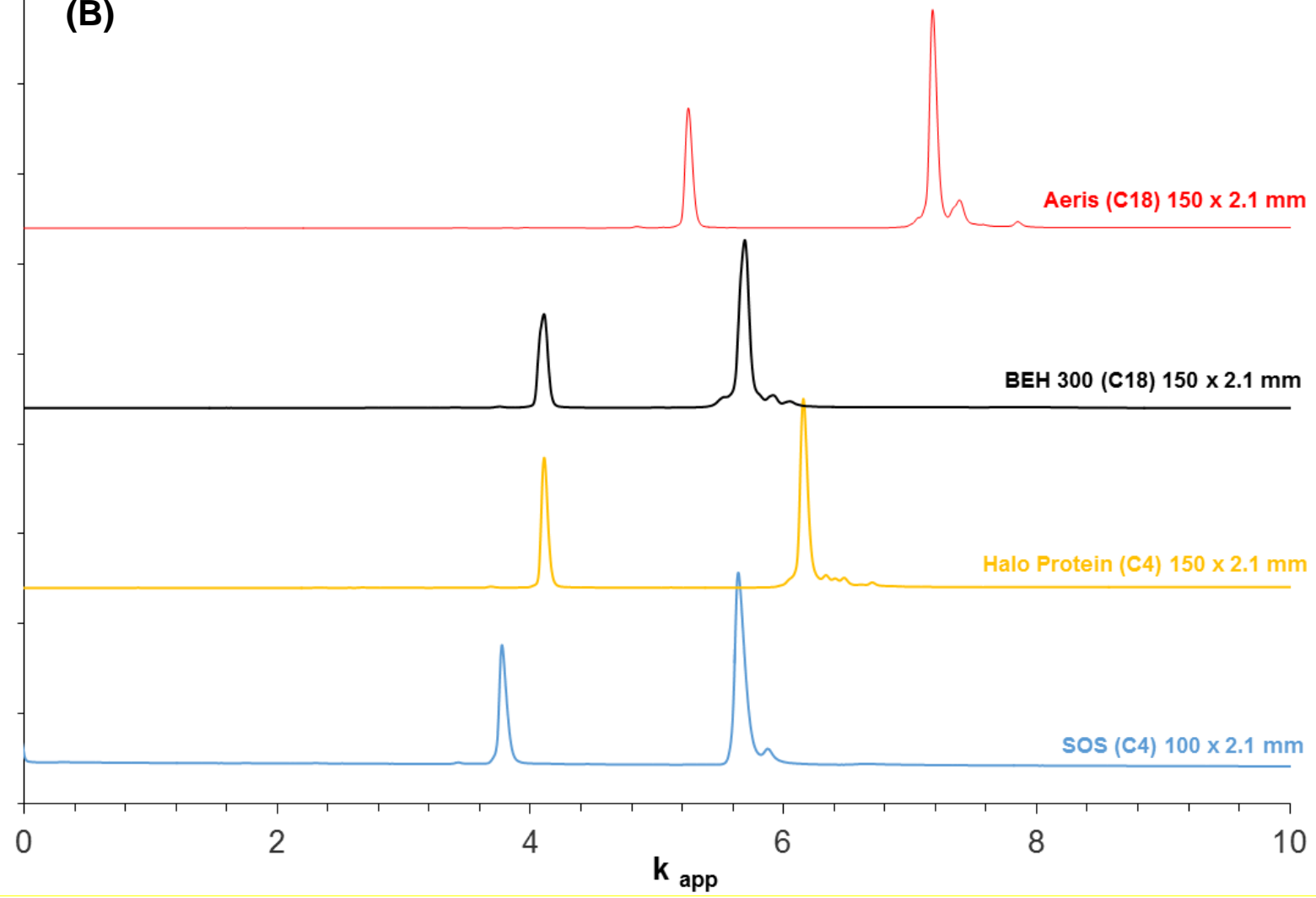

Figure 8. 


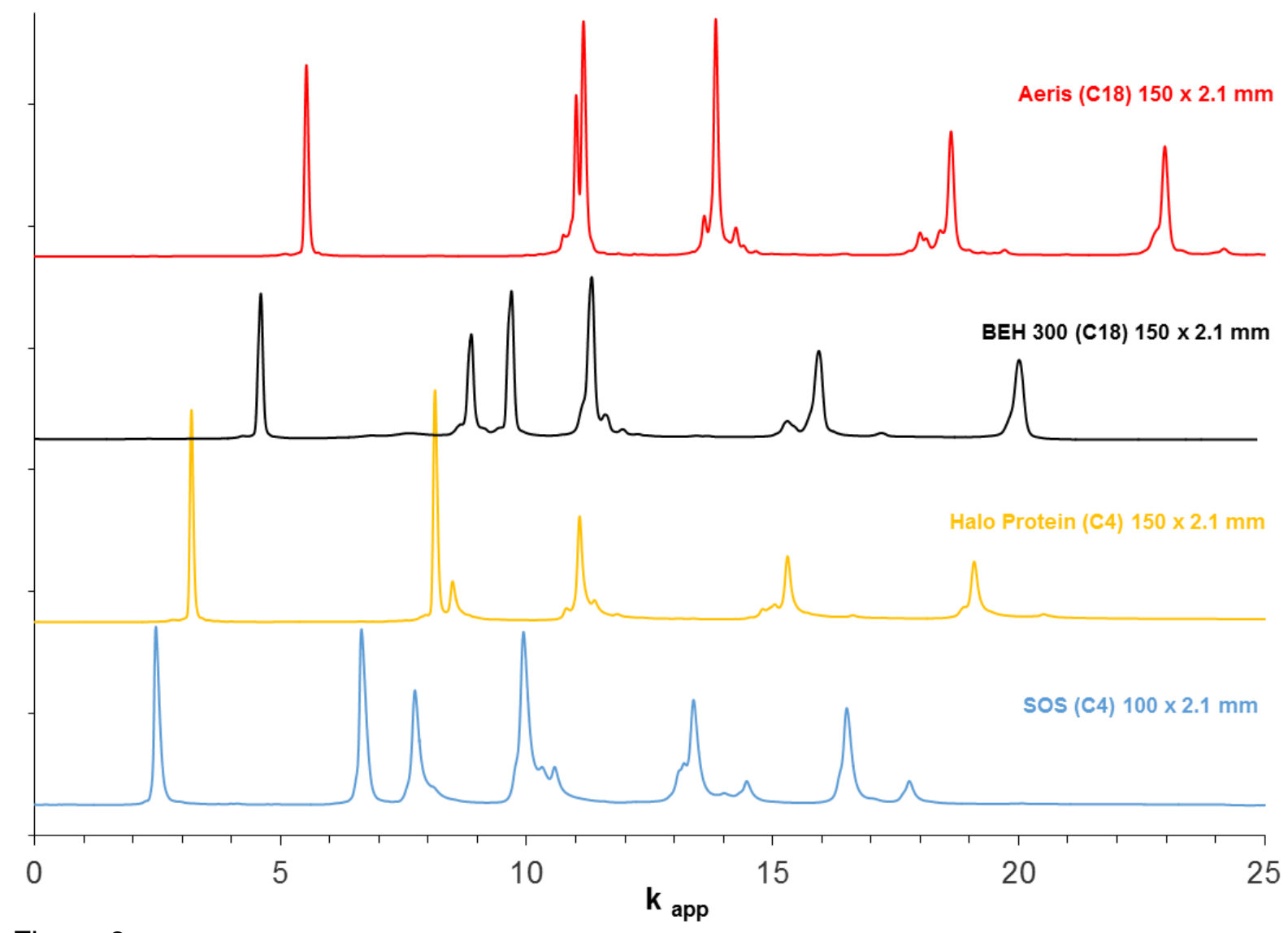

Figure 9. 